correct, as the plasma concentration of vitamin $\mathrm{A}$ is closely controlled.

The multi-infarct group had an intermediate mean plasma carotene concentration and showed no significant correlation between plasma carotene and plasma vitamin A concentrations (Spearman coefficient 0.32 ). These findings very probably result from including patients who also have Alzheimer's disease in the multi-infarct group. ${ }^{5}$

The cause of carotenaemia in Alzheimer's disease is unclear. Although there is considerable overlap ' with other groups, increased plasma carotene con- centrations may be useful as a diagnostic criterion for Alzheimer's disease.

1 Singh S, Mulley GP, Losowsky MS. Why are Alzheimer patients thin? Age Ageing 1988;17:21-8.

2 Haing Neurol 1975;32:632-7.

. 4 Robboy MS, Sato AS, Scwabe AD. The hypercarotenaemia in anorexia nervosa: a comparison of vitamin $A$ and carotene levels in various forms of menstrual dysfunction and cachexia. Am $\mathcal{J}$ Clin Nutr 1974;27:362-7.

5 Mölsä PK, Paljarvi L, Rinne JO, Rinne UK, Säko E. Validity of clinical diagnosis in dementia: a prospective clinicopathological study. $\mathcal{f}$ Neurol Neurosurg Psychiatry 1983;48:1085-90.

(Accepted 12 April 1988)

\title{
Fatal pulmonary aspiration of oral activated charcoal
}

\section{G Menzies, A Busuttil, L F Prescott}

Royal Infirmary, Edinburgh EH3 9YW

D G Menzies, MRCP, medical registrar, regional poisoning treatment centre

A Busuttil, FRCPATH, senior lecturer, university departmen of pathology

L F Prescott, FRCP, professor of clinical pharmacology

Correspondence to: Professor Prescott.
Oral activated charcoal is used to limit drug absorption after overdose, and repeated administration may enhance the removal of drugs already absorbed. ${ }^{2}$ Such treatment is normally considered to be safe, and little information is available about complications. We report a case of fatal respiratory failure after pulmonary aspiration of oral activated charcoal.

\section{Case report}

A 58 year old man with a long history of epilepsy, disturbed behaviour, depression, and admissions for self poisoning was found unrousable. He took phenobarbitone, carbamazepine, and clonazepam regularly and was presumed to have taken an overdose. On examination his temperature was $33^{\circ} \mathrm{C}$, pulse rate 60 beats/minute, and blood pressure $110 / 60 \mathrm{~mm} \mathrm{hg}$, and his chest was clear. Response to stimulation was minimal, the gag reflex was present, and there were no focal neurological signs. The arterial oxygen and carbon dioxide tensions while he was breathing $30 \%$ oxygen were $17 \cdot 8$ and $5 \cdot 5 \mathrm{kPa}$ respectively. A chest $x$ ray film and an electrocardiogram were normal. Plasma concentrations of phenobarbitone and carbamazepine were reported as $>220 \mu \mathrm{mol} / \mathrm{l}(>50 \mathrm{mg} / \mathrm{l})$ and $81 \mu \mathrm{mol} / 1$ ( $19 \mathrm{mg} / \mathrm{l})$ respectively.

Gastric lavage was performed. Unfortunately, the molar units in which the phenobarbitone concentration was reported were misinterpreted and a standard regimen of forced alkaline diuresis was started and activated charcoal (Medicoal) administered by nasogastric tube. The position of the tube was checked by aspiration of gastric acid, the head of the bed was raised, and a loading dose of $50 \mathrm{~g}$ charcoal in $200 \mathrm{ml}$ water was given. Subsequently, further doses of $12.5 \mathrm{~g}$ charcoal were administered hourly after aspiration of the stomach contents. Vomiting occurred 12 hours later with pulmonary aspiration of gastric contents. The trachea was intubated and charcoal suctioned out of the upper airways. With the airway protected further charcoal was given through the nasogastric tube. Chest physiotherapy was given and intravenous flucloxacillin and metronidazole started. His condition improved, and at 48 hours he was alert and orientated.

Over the next 24 hours fever and tachycardia developed, and his arterial oxygen and carbon dioxide tensions were $7 \cdot 7 \mathrm{kPa}$ and $5.3 \mathrm{kPa}$ respectively while he was breathing $40 \%$ oxygen. A chest $x$ ray film showed generalised bilateral opacities (figure), and lung function deteriorated progressively. Assisted ventilation was started on day 8 but was withdrawn five days later after he suffered a major stroke. The neurological deficit and severe respiratory impairment persisted, and chest $x$ ray films showed severe abnormalities; he died 15 days after admission.



Chest $X$ ray film showing bilateral pulmonary infiltrates 48 hours after aspiration of activated charcoal

Necropsy findings included recent cerebral infarction, aspiration pneumonia, diffuse pulmonary thromboembolism, and chronic obstructive airways disease. Microscopic examination of the lungs showed inflammatory changes with charcoal and crystalline material lying free within alveoli, in alveolar macrophages and histiocytes, and in the sinusoidal histiocytes of the regional lymph nodes.

\section{Comment}

Repeated oral administration of activated charcoal is considered to be a simple, safe, and effective means of increasing the elimination of many drugs taken in overdose. The charcoal is, however, unpalatable and must be given by nasogastric tube in unconscious patients. Vomiting can occur,. and although pulmonary aspiration of charcoal is rare, it can cause obstruction, shunting of blood, and hypoxaemia, which may be exacerbated by aspiration of gastric acid. ${ }^{34}$

Medicoal contains povidone as a non-absorbable suspending agent. This can cause chronic inflammatory reactions and has been implicated in pneumonitis after inhalation of hairsprays. ${ }^{5}$ In our patient aspiration of activated charcoal resulted in progressive and ultimately fatal respiratory failure. The pronounced reaction in the pulmonry alveoli and associated lymph nodes presumably accentuated pre-existing damage and precipitated respiratory failure. The airway should be protected when activated charcoal is given, par- 
ticularly when the preparation contains povidone. Unfortunately, our patient died from complications of unnecessary treatment given because the unfamiliar molar units used to report the phenobarbitone concentration were misinterpreted.

ADDENDUM-Since writing this report we have encountered a further case of serious but eventually reversible respiratory failure in a 46 year old man after aspiration of . Medicoal.

\section{Lyme disease with acute purulent meningitis}

\author{
S J Bourke, A G Baird, F J Bone, D R Baird, \\ R D Stevenson
}

Departments of

Respiratory Medicine and

Microbiology, Glasgow

Royal Infirmary, Glasgow

G31 2ES

S J Bourke, MRCPI, medical

registrar

D R Baird, MRCPATH, consultant microbiologist

R D Stevenson, FRCP,

consultant physician

Garrick Hospital, Stranraer

A G Baird, MRCGP, general practitioner

Dumfries and Galloway

Royal Infirmary, Dumfries

F J Bone, FRCPATH,

consultant microbiologist

Correspondence to: $\mathrm{Dr}$ Bourke.
Anonymous. Repeated oral activated charcoal in acute poisoning. Lancet 1987;i:1013-5.

2 Boldy DAR, Vale JA, Prescott LF. Treatment of phenobarbitone poisoning with repeated oral activated charcoal. Of Med 1986;61:997-1002

3 Pollack MM, Dunbar BS, Holbrook PR, Fields AI. Aspiration of activated charcoal and gastric contents. Ann Emerg Med 1981;10:528-9.

4 Dunbar BS, Pollack MM, Shavari MB. Cardiorespiratory changes after charcoal aspiration. Crit Care Med 1981;9:221.

5 Bergmann M, Flance IJ, Cruz PT, et al. Thesaurosis due to inhalation of hairspray. Report of 12 new cases, including three autopsies. $N$ Engl f Med 1962;266:750-5.

(Accepted 12 April 1988
Cases of Lyme disease with neurological manifestations have recently been reported in Britain ${ }^{12}$ and were well documented in the original reports of this disease from Connecticut. ${ }^{3}$ These neurological complications consist of a chronic lymphocytic meningitis often associated with cranial and peripheral neuritis. We report a case of Lyme disease with the undescribed complication of acute purulent meningitis.

\section{Case report}

A 69 year old man presented in May 1987 with a two month history of cough, haemoptysis, and pleuritic pain. He was under regular review for a transitional cell tumour of the bladder and had suffered a myocardial infarction six months earlier. A chest radiograph showed left upper lobe consolidation, but sputum cultures were negative. Appearances at bronchoscopy were normal, and transbronchial biopsy specimens showed an interstitial pneumonitis. Seven days after bronchoscopy he was readmitted to hospital with severe headache, photophobia, a fever of $38.5^{\circ} \mathrm{C}$, and severe neck stiffness. The peripheral white cell count was $16 \cdot 8 \times 10^{\circ} / 1(89 \%$ polymorphs $)$, and lumbar puncture yielded a purulent cerebrospinal fluid containing $2750 \times 10^{9}$ polymorphonuclear leucocytes per litre: protein concentration was raised at $1.6 \mathrm{~g} / \mathrm{l}$ and glucose reduced at $2 \cdot 1 \mathrm{mmol} / 1$ (blood glucose $8.2 \mathrm{mmol} / \mathrm{l}$ ). No organisms were seen on Gram, auramine, or Ziehl-Neelson staining. Latex coagglutination testing (Inverclyde Biologicals) of the cerebrospinal fluid was negative for pneumococcal capsular antigen, cultures of cerebrospinal fluid and blood remained sterile, and serological testing for viruses and Mycoplasma pneumoniae gave negative results.

He was given ampicillin and chloramphenicol for 14 days and antituberculous treatment (rifampicin, pyrazinamide, and isoniazid) for the first six days. A repeat lumbar puncture after seven days showed a fall in the polymorphonuclear count to $1020 \times 10^{9} / 1$. He developed a transient right facial palsy. Serial computed tomograms showed the development of an area of infarction in the right parietal region. A repeat chest radiograph showed resolution of the original consolidation. He made a partial recovery, but three months later, having returned to the care of his general practitioner, he remained disorientated, ataxic, and incontinent. Serological tests at this stage, arranged by his general practitioner, showed IgM antibodies to Borrelia burgdorferi at a titre of $1 / 512$ by indirect immunofluorescence. Retrospective examination of serum obtained at the time of his acute meningitis gave negative results, while serum taken five months later showed IgG but not IgM antibody at a titre of $1 / 256$, indicating a recent infection occurring around the time of the meningitis. He was negative for antinuclear antibodies, rheumatoid factor, and leptospira antibodies, and gave negative results to Treponema pallidum haemagglutination and Venereal Disease Research Laboratory tests. Six months after the initial presentation, when he had almost fully recovered, he developed a peripheral neuritis with a right foot drop, which improved after treatment with intravenous benzylpenicillin $12 \mathrm{MU}$ daily for two weeks. He recalled having had several tick bites while working on his farm but gave no history of a rash or arthropathy.

\section{Comment}

Our patient probably had Lyme disease complicated by acute pyogenic meningitis, though this has not been described before. He had the classic triad of neurological manifestations-meningitis, cranial neuritis, and late peripheral neuritis ${ }^{3}$ - and his serological findings were consistent with recent infection by $B$ burgdorferi. Other known causes of serological cross reactivity such as syphilis and leptospirosis were excluded ${ }^{4}$

We do not know why this patient responded to infection with $B$ burgdorferi with acute pyogenic meningitis, cerebral infarction suggestive of an associated vasculitis, and possibly pneumonitis. The virulence of the infecting organism may be relevant. North American and European strains of $B$ burgdorferi differ in their major proteins so we may expect to see differences between the disease in the United States and Britain. ${ }^{5}$ Erythema chronicum migrans and arthropathy are less common in European than in American cases. 5 At this stage in our knowledge of Lyme disease in Britain we would draw attention by this report to unusual presentations of the disease, which may reflect differences from the syndrome originally described in Connecticut.

We thank Dr D J M Wright, Charing Cross Hospital, London, for his help in performing and interpreting the serological tests.

1 Williams D, Rolles CJ, White JE. Lyme disease in a Hampshire child-medical curiosity or beginning of an epidemic? $\mathrm{Br}$ Med $\mathcal{F}$ 1986;292:1560-1

2 Bateman DE, White JE, Elrington G, Lawton NF. Three further cases of Lyme disease. Br Med J 1987;294:548-9.

3 Pachner AR, Steere AC. The triad of neurologic manifestations of Lyme disease: meningitis, cranial neuritis and radiculoneuritis. Neurology 1985; 35:47-53

4 Muhleman MF, Wright DJM, Black C. Serology of Lyme disease. Lancet $1986 ; \mathrm{i}: 553-4$.

5 Barbour AG, Heiland RA, Nowe TR. Heterogeneity of major proteins in Lyme disease Borreliae: a molecular analysis of North American and European isolates. F Infect Dis 1985;152:478-84.

(Accepted 5 May 1988 